\title{
Substitution of citrate with tissue plasminogen activator (rt-PA) for catheter lock does not improve patency of tunnelled haemodialysis catheters in a randomised trial
}

\author{
Pavlina Richtrova ${ }^{1,2^{*}}$ (D) Jan Mares ${ }^{1,2}$, Lukas Kielberger ${ }^{1,2}$, Jan Klaboch ${ }^{1,2}$, Jaromir Eiselt ${ }^{1,2}$ and Tomas Reischig ${ }^{1,2}$
}

\begin{abstract}
Backround: The study aim was to establish if substitution of citrate with rt-PA for catheter lock once weekly can reduce the incidence of catheter-related blood stream infections (CR-BSI) or improve patency of tunneled haemodialysis catheters.

Methods: All incident patients undergoing insertion of a tunneled haemodialysis catheter were screened and included except those suffering infection or using oral anticoagulation. Study participants were randomized into two arms according to the solution applied as catheter lock: receiving either trisodium citrate (Citra-LockTM 4\%) only or rt-PA (Actilyse ${ }^{\oplus} 1 \mathrm{mg} / \mathrm{ml}$ ) on the middle session each week with citrate used on the first and third sessions. The incidence of CR-BSI (confirmed by positive blood culture), catheter non-function (complete obstruction), and malfunction (blood flow $<250 \mathrm{ml} / \mathrm{min}$ ) was recorded. Statistical significance was tested with ANOVA, post hoc analysis was performed by means of multiple linear regression.
\end{abstract}

Results: Totally, 18 patients were included and followed during 655 haemodialysis sessions. No episode of CR-BSI was detected while 6 catheter non-functions ( $0.9 \%$ sessions) and 101 malfunctions (15.4\% sessions) were recorded. The incidence of both events was equal between the study arms: 4 non-functions and 55 malfunctions in the rt-PA arm and 2 non-functions and 46 malfunctions in the citrate arm ( $p=0.47$ and $p=0.24$, respectively). Additionally, the mean blood flow achieved did not differ significantly between the arms: $326 \pm 1,8$ and $326 \pm 1,9 \mathrm{ml} / \mathrm{min}(p=0.95)$ in rt-PA and citrate arms, respectively. Post hoc analysis identified time elapsed since previous session $(\beta=0.12, p=0.005)$ and malfunction on previous session $(\beta=0.25, p<0.001)$ as significant factors affecting the occurrence of malfunction. By contrast, the study arm, rt-PA application on previous session, and catheter vintage did not enter the model.

(Continued on next page)

\footnotetext{
* Correspondence: richtrovap@fnplzen.cz

'Department of Internal Medicine I, Faculty of Medicine in Pilsen, Charles University, and Teaching Hospital in Pilsen, Alej Svobody 80, 30460 Plzen, Czech Republic

${ }^{2}$ Biomedical Centre, Faculty of Medicine in Pilsen, Charles University, Pilsen,

Czech Republic
}

(c) The Author(s). 2021 Open Access This article is licensed under a Creative Commons Attribution 4.0 International License, which permits use, sharing, adaptation, distribution and reproduction in any medium or format, as long as you give appropriate credit to the original author(s) and the source, provide a link to the Creative Commons licence, and indicate if changes were made. The images or other third party material in this article are included in the article's Creative Commons licence, unless indicated otherwise in a credit line to the material. If material is not included in the article's Creative Commons licence and your intended use is not permitted by statutory regulation or exceeds the permitted use, you will need to obtain permission directly from the copyright holder. To view a copy of this licence, visit http://creativecommons.org/licenses/by/4.0/ The Creative Commons Public Domain Dedication waiver (http://creativecommons.org/publicdomain/zero/1.0/) applies to the data made available in this article, unless otherwise stated in a credit line to the data. 
(Continued from previous page)

Conclusion: Substitution of citrate with rt-PA for catheter lock does not reduce the incidence of catheter malfunction neither does it affect the blood flow achieved during haemodialysis. Catheter patency is related rather to the time interval between sessions and to previous malfunction (thus probably reflecting undefined individual factors). The incidence of CR-BSI within pre-selected haemodialysis population is sporadic (less than 1 per 4.3 patient years in our sample).

Trial registration: Australian New Zealand Clinical Trials Registry, ACTRN12612000152820. Retrospectively registered 03/02/2012.

\section{Background}

A number of guidelines and initiatives strongly recommend native arteriovenous fistulas (AVF) and discourage the use of catheters for chronic dialysis treatment [1-3]. This fistula first policy is based on evidence from large observational studies showing that the use of AVF is associated with the lowest (and catheters with the highest) risk of death from infection and cardiovascular disease $[4,5]$. However, in contrast to this recommendation, the proportion of haemodialysis (HD) patients treated with central venous catheters $(\mathrm{CVC})$ is increasing $[6,7]$. It is related to the ageing of the HD population and its polymorbidity. The quality of the vascular system is poor, the creation of AVF is difficult, and the maturation is not successful enough. Up to $60 \%$ of AVFs fail immediately after surgery or fail to mature $[8,9]$. Noordzij et al. found that female patients and those $>80$ years were least likely to start HD with an AVF, according to European renal registries between 2005 and 2009 [6].

An alternative to AVF for chronic HD treatment is tunnelled CVC (tCVC). It can serve as temporary access until the maturation of AVF, or it is definitive option for patients without the possibility for native access. Care for patients with tCVC means, in particular, prevention of exit site infection and catheter-related blood stream infection (CRBSI), and care for catheter patency. In addition to common rules of asepsis, catheter lock solutions are used. These solutions consist of various chemicals and are installed after every HD procedure to tCVC at a volume precisely declared on the catheter. Evidence to guide catheter lock solutions is limited. In recent years, there has been a shift from the use of heparin to citrate solutions [10].

In 2011, Hemmelgarn and colleagues demonstrated a beneficial effect of once-weekly recombinant tissue plasminogen activator (rt-PA) to reduce the incidence of tCVC malfunctions and bacteraemia [11]. At that time, rt-PA was compared with heparin locks. Later, the same authors found a significant reduction in the rate of rtPA use for treatment of catheter malfunction using once-weekly rt-PA as a locking solution, compared with thrice-weekly heparin and citrate only [12]. Unlike the first study, there was no evidence of a significant effect on the occurrence of bacteraemia (in the risk incident and prevalent HD patients). A certain limitation of the rt-PA lock is its higher cost (a difference of CAD\$962 per enrolment in the last relevant study). Based on these results we have decided to realize a prospective study (to assess the effectiveness of rt-PA once a week as a locking solution, as compared with $4 \%$ citrate only for prevention of CRBSI and catheter dysfunction) in the conditions of our local HD centre.

\section{Methods}

The study was randomised, prospective, and double blinded. All incident patients undergoing insertion of tCVC in the Haemodialysis Centre at Charles University Teaching Hospital in Plzen were screened and included, except those with exclusion criteria: anticoagulation treatment, INR more than 1.4, platelets less than $60 \times$ $10^{9} / 1$, clinical symptoms of infection, known malignancy, catheter insertion in vena cava inferior region (femoral vein), bleeding complication in the four weeks before catheter insertion, major surgery in the past $48 \mathrm{~h}$, major surgery planned in the next 6 months, active pericarditis and known allergy or intolerance to alteplase or trisodium citrate, and pregnancy or breastfeeding. Study participants were randomised by block method into two groups (1:1, four patients in one block) according to the solution applied as a catheter lock: 1) receiving either trisodium citrate (Citra-LockTM 4\%) only or 2) rt-PA (Actilyse $1 \mathrm{mg} / \mathrm{ml}$, volume adjusted with saline to match the lumen) in the middle session each week with citrate used in the first and third sessions. The locks were prepared by an independent pharmacist, so both participants and medical staff were unaware of their compositions until the study ended.

To calculate the sample size, the number of patients was calculated in relation to the primary endpoint of the study, which is the incidence of CRBSI at the end of the sixth month after the insertion of the permcath. The basic hypothesis of the study is the assumption that rtPA will lead to a reduction in the risk of CRBSI compared to sodium citrate. In the sodium citrate group, the incidence of CRBSI is assumed to be $15 \%$. Sixty-five (power $=0.80$; alpha $=0.05)$ patients are needed to detect 
a reduction in incidence of $5 \%$ or less. Due to the assumption of patient losses from follow-up, the plan is to include 80 patients. Preliminary analysis of the results with a change of protocol was not planned.

The primary outcome was the incidence of CRBSI. We modified the definition according to the Canadian definitions for catheter-related infections [13]. The definition of definite CRBSI was 1) positive blood culture from catheter and peripheral blood, and positive culture from discharge or aspirate from exit site or tunnel with identical organism, 2) positive blood culture and positive culture of catheter segment with identical organism, 3) positive blood culture and septic thrombophlebitis, or 4) positive blood culture from peripheral blood and catheter (with the identical organism) that meet the criteria for differential time to positivity (DTP) = the positivity of catheter blood culture comes at least two hours earlier. The definition of probable CRBSI was 1) two or more positive blood cultures (peripheral blood and catheter) with no evidence of source other than catheter, 2) single positive blood culture (peripheral blood or catheter) for $\mathrm{G}+$ coccus with no evidence of source other than catheter, 3) strong clinical suspicion of bacterial infection with the source in the catheter (symptoms manifesting during dialysis procedure) with the necessary exclusion of other sources (urogenital and respiratory system), or 4) positive blood culture from peripheral blood and catheter (with the identical organism) that don't meet the criteria of DTP for definite CRBSI .

The secondary outcome was the incidence of catheter malfunction/obstruction. We again modified the definition of Hemmelgarn et al. according to the K/DOQI guidelines that was defined as 1) maximal blood flow (BF) $250 \mathrm{ml} / \mathrm{min}$ or less for $30 \mathrm{mins}$ or more during one dialysis procedure ( $\max$ arterial and venous pressure limits of $-250 \mathrm{mmHg}$ and $+250 \mathrm{mmHg}$, respectively), 2) mean BF $250 \mathrm{ml} / \mathrm{min}$ or less during two consecutive dialysis procedures ( $\max$ arterial and venous pressure limits of - $250 \mathrm{mmHg}$ and $+250 \mathrm{mmHg}$, respectively), 3) Reversal to catheter lines as a solution to start the dialysis with $\mathrm{BF}$ at least $200 \mathrm{ml} / \mathrm{min}$ (max arterial and venous pressure limits of $-250 \mathrm{mmHg}$ and $+250 \mathrm{mmHg}$ respectively), or 4) inability to initiate dialysis because of catheter obstruction for at least $200 \mathrm{ml} / \mathrm{min}$, even after the reversal of catheter lines (max arterial and venous pressure limits of $-250 \mathrm{mmHg}$ and $+250 \mathrm{mmHg}$ respectively) $[14,15]$. Treatment-related adverse effects (bleeding, hypersensitivity) were recorded. The blood flow achieved (and sustained) during the dialysis session was logged. Malfunctions were treated by application of Actilyse $^{\circ} 1 \mathrm{mg}$ into one or both lumens according to the study protocol.

The results are presented as arithmetical means (standard errors of the mean). Statistical significance was tested with ANOVA, and post hoc analysis was performed by means of multiple linear regression. All calculations were performed using Statistica 8.0 (Stat Soft, Inc.). The study was registered at ANZCTR (ACTR N12612000152820) on the 3rd of February 2012, approved by the local Ethics Committee at Charles University Teaching Hospital in Plzen and conducted in compliance with the Declaration of Helsinki and Declaration of Istanbul. All participants were above 18 years of age and signed an informed consent form.

\section{Results}

Eighteen patients (mean age $67 \pm 15.1$ years, $50 \%$ males) were included and followed during 655 haemodialysis sessions between March 2012 and December 2016. The main reason for not reaching the intended numbers was an unexpected absence of CRBSI episodes and a high proportion of patients meeting the exclusion criteria. While it made analysis of the primary endpoint unfeasible (even in the extended recruitment period), evaluation of the secondary endpoint was possible. No episode of CRBSI was detected, making the incidence less than 1 in 4.3 patient years. However, it should be acknowledged that these figures may be underestimating the real occurrence due to selection bias. At the same time, six catheter non-functions ( $0.9 \%$ sessions) and 101 malfunctions ( $15.4 \%$ sessions) were recorded, and no significant difference was found comparing the group with citrate and rt-PA (Fig. 1). The incidence of both events was equal between the study groups: 4 non-functions and 55 malfunctions in the rt-PA arm and 2 nonfunctions and 46 malfunctions in the citrate $\operatorname{arm}(p=$ 0.47 and $p=0.24$, respectively). Additionally, the mean blood flow achieved did not differ significantly between the groups: $326 \pm 1,8$ and $326 \pm 1,9 \mathrm{ml} / \mathrm{min}(p=0.95)$ in the rt-PA and citrate groups, respectively. Post hoc analysis identified time elapsed since previous session $(\beta=$ $0.12, p=0.005)$ and malfunction on previous session $(\beta=0.25, p<0.001)$ as significant factors affecting the occurrence of malfunction (Table 1). Thus, administration of the rt-PA after the middle HD procedure did not affect the incidence of malfunction or tCVC afunction and did not affect the treated blood volume or blood flow during HD (Figs. 2 and 3).

\section{Discussion}

Most valid recommendations indicate the native AVF as vascular access for chronic dialysis treatment [1-3]. However, the number of patients with $\mathrm{tCVC}$ is high, and depending on the source, accounts for up to $80 \%$ of patients initiating HD treatment [16-18]. The main complications associated with $\mathrm{tCVC}$ are infections and thrombotic occlusions [19]. The problem of patency reduces the effectiveness of dialysis, and both of these 


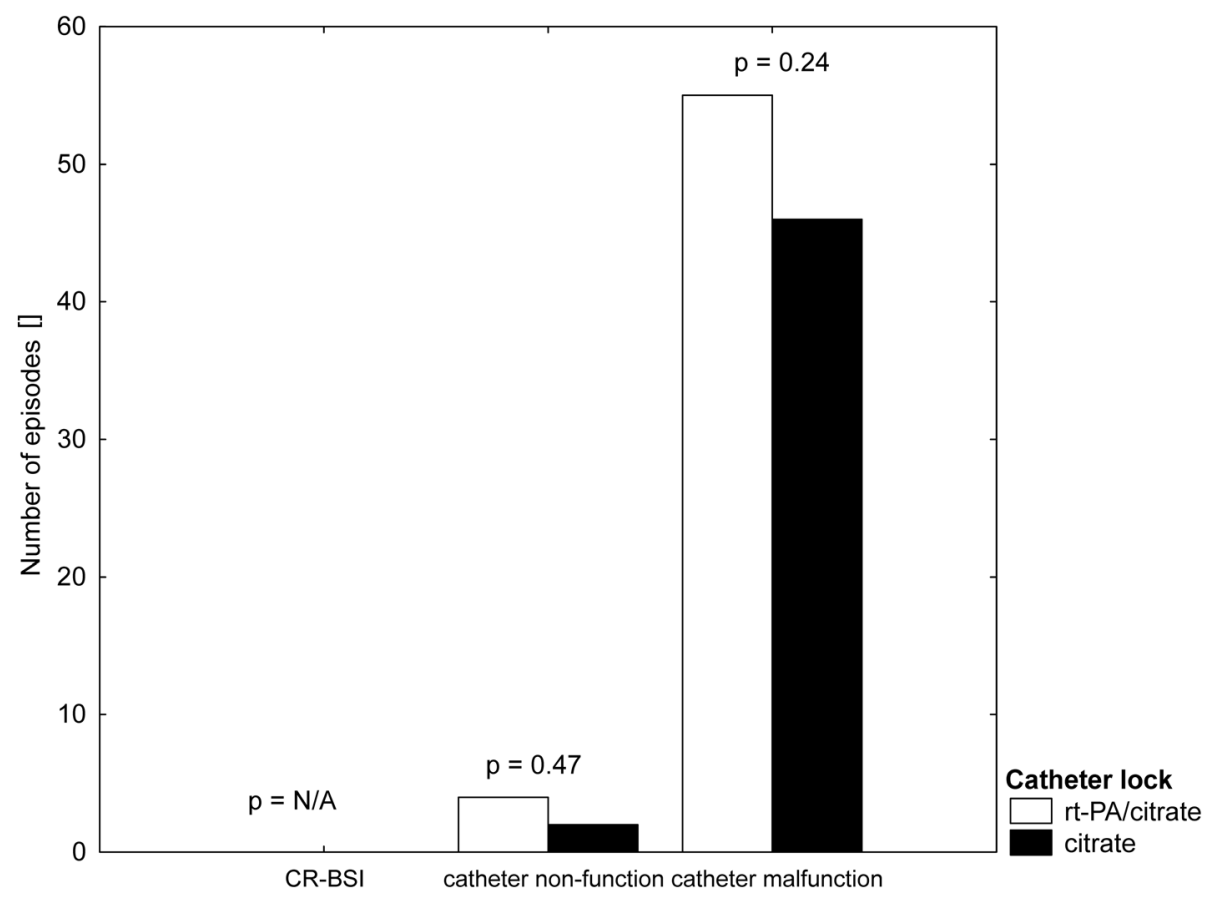

Fig. 1 Primary (CR-BSI episodes) and secondary (catheter dysfunction) endpoints reached during the study

complications increase the morbidity and mortality of dialysed patients [20]. The frequency of bacteraemia is reported with rates of 2.7 per 1000 catheter days in the first month of catheter use, and 0.4 per 1000 catheter days for $>12$ months [21]. The target should be a rate lower than one episode of CRBSI per 1000 catheter days [22]. In the present study, all patients were newly enrolled in the HD programme, and the bacteraemia rate of less than 0.64 per 1000 catheter days is therefore quite satisfactory. In the context of other studies, tCVCs may be considered relatively safe $[11,12]$. This is in contradiction with general recommendations to avoid tCVC where possible, but as mentioned previously, for some types of people requiring dialysis, $\mathrm{tCVC}$ is a better alternative $[23,24]$. These include, in particular, patients of advanced age with severe sclerotic lesions, often with relatively short life prospects or even considering palliative nephrology care. Under these circumstances, it is certainly not appropriate to set AVF in advance for many months, but it is better to wait for further courses. If necessary, $\mathrm{tCVC}$ is the best and often most lasting solution for initiating HD treatment. The results of this study, with their low incidence of CRBSI, further support this approach.

An important part of $\mathrm{tCVC}$ care is an aseptic approach in general and local exit site care. The aim of catheter locks is to ensure the patency of tCVC at the time of $\mathrm{HD}$, and as far as possible, to reduce possible infection complications. In the context of these requirements, the composition of the locks has evolved over time. In the past, heparin was the most commonly used, but in recent years, prevalence has shifted to citrate [10]. Higher citrate concentrations $(30,46.7 \%)$ were withdrawn by FDA for possible association with serious adverse effects, and citrate locks with $4 \%$ concentration are now most commonly used $[25,26]$. This solution appears to be

Table 1 Multiple linear regression, catheter malfunction as dependent variable

\begin{tabular}{llll}
\hline Independent variables & $\boldsymbol{\beta}$ & Std.Err. of $\boldsymbol{\beta}$ & p-level \\
\hline Previous malfunction [Y/N] & 0,248 & 0,041 & 0,000 \\
Interval since previous session [days] & 0,122 & 0,044 & 0,005 \\
Catheter vintage [number of sessions passed] & $-0,055$ & 0,042 & 0,186 \\
rt-PA application on previous session [mg] & $-0,068$ & 0,049 & 0,165 \\
Study arm [rt-PA/citrate] & 0,056 & 0,047 & 0,227 \\
\hline
\end{tabular}

Multiple linear regression: $\mathrm{R}=0.2996 \mathrm{R} 2=0.0898$ Adjusted $\mathrm{R} 2=0.0814$

$F(5,542)=10,690 p<0.00000$ Std. Error of estimate: 0.32786 


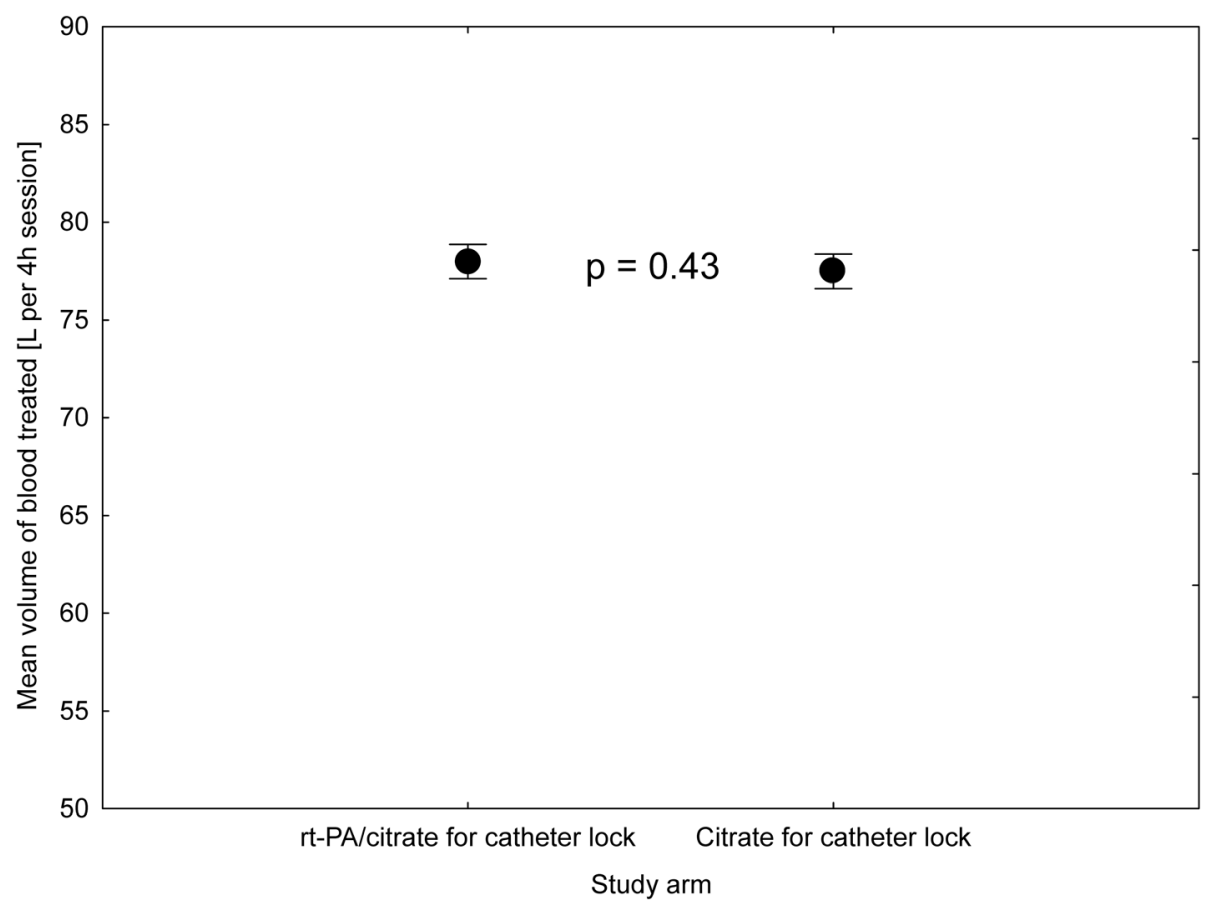

Fig. 2 Mean volume of blood treated during HD session

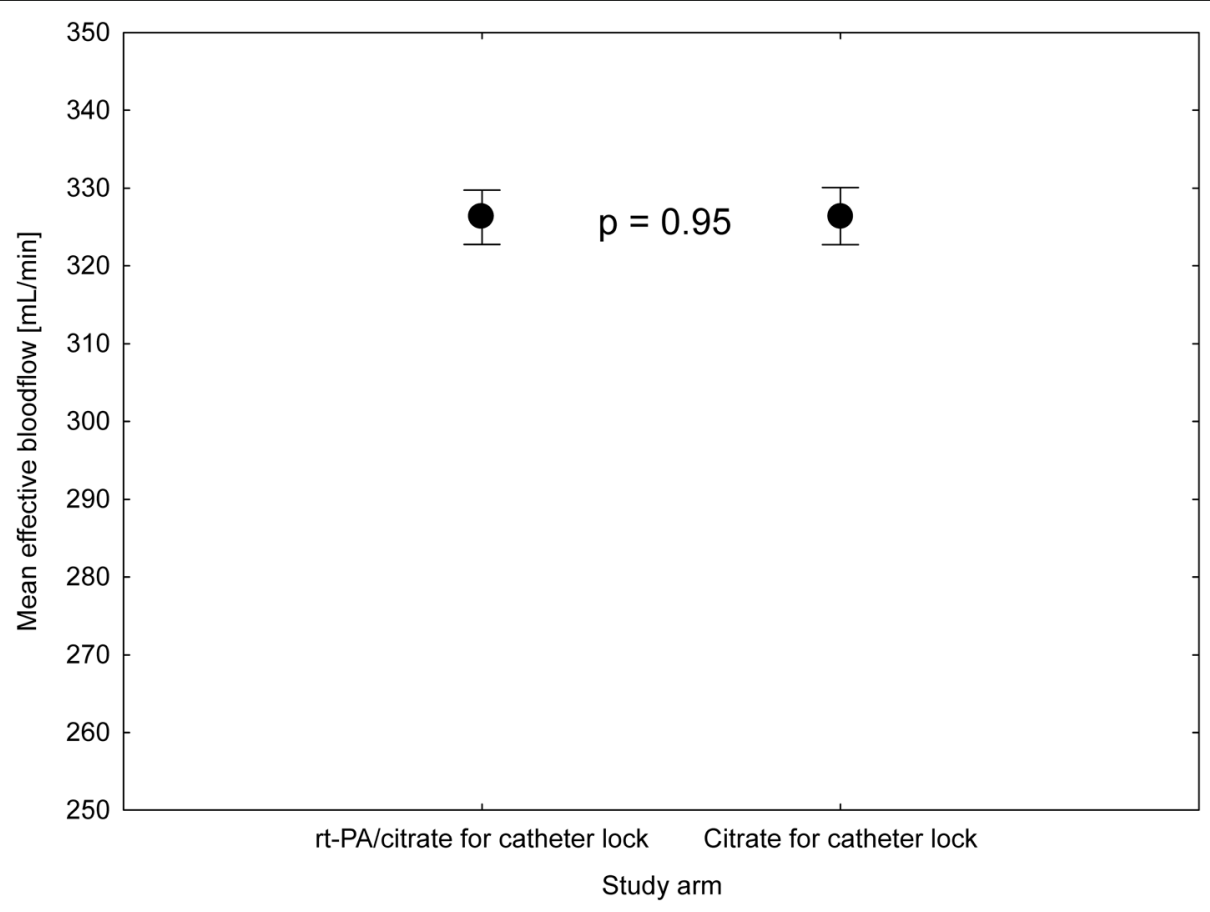

Fig. 3 Mean effective blood flow achieved during HD session 
safe, is relatively inexpensive, and has some antimicrobial activity [26, 27], which is why it is commonly recommended [28]. In the case of acute obstruction of tCVC, use of fibrinolytic agents is recommended (e.g. rtPA [3]. Thus, the question is whether regular administration of fibrinolytic would further affect the malfunction of tCVC or the frequency of CRBSI. Because the major drawback of rt-PA is its high cost, it is usually only used once a week. When compared to heparin locks, the beneficial effects of rt-PA administration has already been shown [11]. In this study, the effect of rtPA compared to citrate locks was verified. However, during the $655 \mathrm{HD}$ procedures in 18 patients, no significant difference was found. The occurrence of malfunctions and afunctions was the same in both study groups. A linear regression found that the length of the interdialytic interval was the most important factor, specifically that the longer the interdialytic interval, the higher the risk of tCVC obstruction. At the same time, if obstruction occurs once, the risk of another obstruction is significantly higher.

Locks containing antibiotics seemed to be promising, but these are not yet generally recommended [29], mainly due to concerns about the risk of resistance. One alternative could be a lock that contains taurolidine. Taurolidine is an antimicrobial chemotherapeutic agent that acts through a chemical reaction with the microbial structure of the cell wall. It has an extremely wide microbial spectrum, including methicillin- and vancomycin-resistant bacteria, and unlike conventional antibiotics, resistance has not yet been observed [30]. However, the position of taurolidine on the field of catheter locks has to be verified by more prospective and randomised trials.

One limitation of the present study is the failure to include the required number of patients. Strict exclusion criteria eliminated most incident patients with tCVC. Another limitation was the very low occurrence of primary outcome. However, the occurrence of CRBSI was low and it can be concluded that tCVC is therefore relatively safe. It appears to be a good alternative to vascular access in patients, particularly with uncertain prognosis and exhausted vascular systems. This is in contradiction with common recommendations, but data from recent clinical practice tends to support this opinion.

\section{Conclusion}

Regular administration of rt-PA once a week does not affect the occurrence of obstruction or malfunction of tCVC compared to citrate locks only. With the low incidence of CRBSI in the present study in general, more cannot be said about the impact on infectious complications. TCVC appears to be relatively safe and should be considered especially for the elderly population or patients with poor and uncertain prognoses, often in association with a devastated native vascular system. Until the results of larger studies with catheter locks are available, especially with taurolidine, this study suggests citrate locks are a valid recommendation.

\section{Funding}

The study was supported by the National Sustainability Programme I [LO1503] provided by the Ministry of Education, Youth and Sports of the Czech Republic, the Charles University Research Fund [Progres Q39], and Project No. CZ.02.1.01/0.0/0.0/16_019/0000787 "Fighting Infectious Diseases "awarded by the MEYS CR, financed by EFRR.

\section{Abbreviations \\ rt-PA: Recombinant tissue plasminogen activator; CR-BSI: catheter-related bloodstream infection; HD: Haemodialysis; AVF: Arteriovenous fistula; CVC: Central venous catheter; tCVC: Tunnelled central venous catheter; DTP: Differential time to positivity; BF: Blood flow}

\section{Acknowledgements}

Not applicable.

\section{Authors' contributions}

a. PR - study protocol, registration, results and statistical analysis, manuscript preparation. b. JM - statistical analysis and results interpretation. c. LK patients' recruitment and randomization. d. JK - patients' recruitment and randomization. e. JE - patients' recruitment, consultant. f. TR - study design, consultant. All authors have read and approved the manuscript.

\section{Funding}

The study was supported by the National Sustainability Programme I [LO1503] provided by the Ministry of Education, Youth and Sports of the Czech Republic, the Charles University Research Fund [PROGRES Q39], and Project No. CZ.02.1.01/0.0/0.0/16_019/0000787 “Fighting Infectious Diseases "awarded by the MEYS CR, financed by EFRR.

\section{Availability of data and materials}

The datasets during and/or analysed during the current study are available from the corresponding author on reasonable request.

Ethics approval and consent to participate

The study was approved by the local Ethics Committee at Charles University Teaching Hospital in Plzen and conducted in compliance with the

Declaration of Helsinki and Declaration of Istanbul. Written informed consent was obtained before enrolment.

Consent for publication

Not applicable.

\section{Competing interests}

The authors declare that they have no competing interests.

Received: 12 October 2020 Accepted: 14 January 2021

Published online: 28 January 2021

References

1. Vascular Access Work Group. Clinical Practice guidelines for vascular access. Am J Kidney Dis. 2006;48(Suppl 1):S176-247.

2. Lee T. Fistula first initiative: historical impact on vascular access practice patterns and influence on future vascular access care. Cardiovasc Eng Technol. 2017;8(3):244-54.

3. National Kidney Foundation. KDOQI Clinical Practice Guidelines and Clinical Practice Recommendations for 2006 Updates: Hemodialysis Adequacy, Peritoneal Dialysis Adequacy and Vascular Access. Am J Kidney Dis. 2006; 48(suppl 1):S1-S322. 
4. Ravani P, Palmer SC, Oliver MJ, et al. Associations between hemodialysis access type and clinical outcomes: a systematic review. J Am Soc Nephrol 2013;24:465-73.

5. Ravani P, Gillespie BW, Quinn RR, et al. Temporal risk profile for infec- tious and noninfectious complications of hemodialysis access. J Am Soc Nephrol. 2013;24:1668-77.

6. Noordzij M, Jager KJ, van der Veer SN, et al. Use of vascular access for haemodialysis in Europe: a report from the ERA-EDTA registry. Nephrol Dial Transplant. 2014;29(10):1956-64.

7. Xue H, Ix JH, Wang W, Brunelli SM, Lazarus M, Hakim R, Lacson E Jr. Hemodialysis access usage patterns in the incident dialysis year and associated catheter-related complications. Am J Kidney Dis. 2013;61(1):123-30.

8. Dember LM, Beck GJ, Allon M, et al. Effect of clopidogrel on early failure of arteriovenous fistulas for hemodialysis: a randomized controlled trial. JAMA. 2008;299:2164-71.

9. Wang W, Murphy B, Yilmaz S, et al. Comorbidities do not influence primary fistula success in incident hemodialysis patients: a prospective study. Clin J Am Soc Nephrol. 2008;3:78-84.

10. Wang Y, Ivany JN, Perkovic V, Gallagher MP, Woodward M, Jardine MJ. Anticoagulants and antiplatelet agents for preventing central venous haemodialysis catheter malfunction in patients with end-stage kidney disease. Cochrane Database Syst Rev. 2016;4:CD009631.

11. Hemmelgarn BR, Moist LM, Lok CE, Tonelli M, Manns BJ, Holden RM, LeBlanc M, Faris P, Barre P, Zhang J, Scott-Douglas N. Prevention of Dialysis catheter lumen occlusion with rt-PA versus heparin study group. Prevention of dialysis catheter malfunction with recombinant tissue plasminogen activator. N Engl J Med. 2011;364(4):303-12.

12. Hemmelgarn BR, Manns BJ, Soroka SD, Levin A, MacRae J, Tennankore K, Wilson JS, Weaver RG, Ravani P, Quinn RR, Tonelli M, Kiaii M, Mossop P, Scott-Douglas N. Effectiveness and cost of weekly recombinant tissue plasminogen activator hemodialysis catheter locking solution. Clin J Am Soc Nephrol. 2018;13(3):429-35.

13. Division of Nosocomial and Occupational Infectious Diseases, Bureau of Infectious Diseases, Laboratory Centre for Disease Control, Health Canada. Preventing infections associated with indwelling intravascular access devices. Can Commun Dis Rep. 1997;23(Suppl 8):i-iii, 1-32, i-iv, 1-16. English, French. PMID: 11195273.

14. Hemmelgarn BR, Moist L, Pilkey RM, Lok C, Dorval M, Tam PY, Berall MJ, LeBlanc M, Toffelmire EB, Manns BJ, Scott-Douglas N, Canadian Hemodialysis Catheter Working Group. Prevention of catheter lumen occlusion with rT-PA versus heparin (Pre-CLOT): study protocol of a randomized trial [ISRCTN35253449]. BMC Nephrol. 2006;7:8. https://doi.org/ 10.1186/1471-2369-7-8 PMID: 16608513; PMCID: PMC1459124.

15. III. NKF-K/DOQI Clinical Practice Guidelines for Vascular Access: update 2000. Am J Kidney Dis. 2001;37(1 Suppl 1):S137-81. https://doi.org/10.1016/s02726386(01)70007-8. PMID: 11229969

16. Canadian Institute for Health Information: Canadian Organ Re- placement Register Annual Report: Treatment of End-Stage Organ Failure in Canada, 2004-2013. Canadian Institute for Health In- formation, 2015. Available at: https:/secure.cihi.ca/ free_products/2015_CORR_AnnualReport_ENweb.pdf. Accessed June 15, 2017.

17. Moist LM, Trpeski L, Na Y, Lok CE. Increased hemodialysis catheter use in Canada and associated mortality risk: data from the Canadian organ replacement registry 2001-2004. Clin J Am Soc Nephrol. 2008;3:1726-32.

18. US Renal Data System: USRDS 2015 Annual Data Report. Methesda, MD: National Institutes of Health: National Institute of Diabetes and Digestive and Kidney Diseases, 2015. Available at: http//mww.usrds.org/2015/view. Accessed June 15, 2017.

19. Butterly DW, Schwab SJ. Dialysis access infections. Curr Opin Nephrol Hypertens. 2000;9(6):631-5.

20. Saran R, Bragg-Gresham JL, Rayner HC, Goodkin DA, Keen ML, Van Dijk PC, Kurokawa K, Piera L, Saito A, Fukuhara S, Young EW, Held PJ, Port FK. Nonadherence in hemodialysis: associations with mortality, hospitalization, and practice patterns in the DOPPS. Kidney Int. 2003;64:254-62.

21. Combe C, Pisoni RL, Port FK, Young EW, Canaud B, Mapes DL, Held PJ. Dialysis Outcomes and Practice Patterns Study: data on the use of central venous catheters in chronic hemodialysis. Nephrologie. 2001;22(8):379-84.

22. Betjes MG. Prevention of catheter-related bloodstream infection in patients on hemodialysis. Nat Rev Nephrol. 2011;7(5):257-65.

23. Chan MR, Sanchez RJ, Young HN, Yevzlin AS. Vascular access outcomes in the elderly hemodialysis population: a USRDS study. Semin Dial. 2007;20(6):606-10.
24. Woo K, Lok CE. New insights into Dialysis vascular access: what is the optimal vascular access type and timing of access creation in CKD and Dialysis patients? Clin J Am Soc Nephrol. 2016;11(8):1487-94.

25. Willicombe MK, Vernon K, Davenport A. Embolic complications from central venous hemodialysis catheters used with hypertonic citrate locking solution. Am J Kidney Dis. 2010;55(2):348-51.

26. Schilcher G, Scharnagl H, Horina JH, Ribitsch W, Rosenkranz AR, Stojakovic T, Polaschegg HD. Trisodium citrate induced protein precipitation in haemodialysis catheters might cause pulmonary embolism. Nephrol Dial Transplant. 2012;27(7):2953-7.

27. Weijmer MC, Debets-Ossenkopp YJ, Van De Vondervoort FJ, ter Wee PM. Superior antimicrobial activity of trisodium citrate over heparin for catheter locking. Nephrol Dial Transplant. 2002;17(12):2189-95.

28. Grudzinski L, Quinan P, Kwok S, Pierratos A. Sodium citrate $4 \%$ locking solution for central venous dialysis catheters--an effective, more costefficient alternative to heparin. Nephrol Dial Transplant. 2007;22(2):471-6.

29. Vanholder R, Canaud B, Fluck R, Jadoul M, Labriola L, Marti-Monros A, Tordoir J, Van Biesen W. Diagnosis, prevention and treatment of haemodialysis catheterrelated bloodstream infections (CRBSI): a position statement of European Renal Best Practice (ERBP). NDT Plus. 2010;3(3):234-46.

30. Torres-Viera C, Thauvin-Eliopoulos C, Souli M, DeGirolami P, Farris MG, Wennersten CB, Sofia RD, Eliopoulos GM. Activities of taurolidine in vitro and in experimental enterococcal endocarditis. Antimicrob Agents Chemother. 2000;44(6):1720-4.

\section{Publisher's Note}

Springer Nature remains neutral with regard to jurisdictional claims in published maps and institutional affiliations.

\section{Ready to submit your research? Choose BMC and benefit from:}

- fast, convenient online submission

- thorough peer review by experienced researchers in your field

- rapid publication on acceptance

- support for research data, including large and complex data types

- gold Open Access which fosters wider collaboration and increased citations

- maximum visibility for your research: over $100 \mathrm{M}$ website views per year

At BMC, research is always in progress.

Learn more biomedcentral.com/submissions 